Article

\title{
New Requirements of the Voltage/VAR Function for Smart Inverter in Distributed Generation Control
}

\author{
Yun-Su Kim *, Gyeong-Hun Kim, Jae-Duck Lee and Changhee Cho \\ Korea Electrotechnology Research Institute, Changwon 51543, Korea; kgh1001@keri.re.kr (G.-H.K.); \\ jdlee@keri.re.kr (J.-D.L.); chcho@keri.re.kr (C.C.) \\ * Correspondence: ysk0822@keri.re.kr; Tel.: +82-55-280-1316
}

Academic Editor: Ying-Yi Hong

Received: 19 July 2016; Accepted: 4 November 2016; Published: 9 November 2016

\begin{abstract}
International Electronical Committee (IEC) 61850-90-7 is a part of the IEC 61850 series which specifies the advanced functions and object models for power converter based Distributed Energy Resources (DERs). One of its functions, the Voltage/VAR (V/V) control function, is used to enhance the stability and the reliability of the voltage in the distribution system. The conventional V/V function acts mainly for flattening the voltage profile as for a basic grid support function. Currently, other objectives such as the minimization of line loss and the operational costs reduction are coming into the spotlight. In order to attain these objectives, the V/V function and hence the DER units shall actively respond to the change of distribution system conditions. In this paper, the modification of $\mathrm{V} / \mathrm{V}$ function and new requirements are proposed. To derive new requirements of $\mathrm{V} / \mathrm{V}$ function, loss minimization is applied to a particle swarm optimization (PSO) algorithm where the condition of voltage constraint is considered not to deteriorate the voltage stability of the distribution system.
\end{abstract}

Keywords: International Electronical Committee 61850; inverter-interfaced distributed generation; smart inverter; Volt/VAR function

\section{Introduction}

Distributed Generations (DGs) have continuously increased due to immense use of electrical energy, exhaustion of fossil fuels, environmental pollutions, and other economic factors. Numerous projects have been implemented in a test-bed scale and many of these have been successfully deployed on a commercial scale. The penetration level of renewable energy sources in both Norway and Sweden has already exceeded $30 \%$ since 2012 and in the case of the US, the generation capacity of photovoltaic (PV) systems has exceeded 10 GW since 2013 [1,2]. In the case of Denmark, wind power's share of total power consumption is expected to be approximately $50 \%$ by 2020 and the Danish government has proposed a goal of $100 \%$ renewable energy sources in 2050 [3].

High-level penetration of the renewable energy sources consequently deteriorates grid stability. Therefore, grid operators and the authorities limit the amounts of renewable energy sources and are making new grid code requirement to maintain the stability and the security of the power grid. Low-Voltage Ride-Through (LVRT) is one of the new requirements for DGs, and ensures the DGs stay connected with the grid in the case of small and not very long voltage dip events. It prevents cascading DG dropout from a small fault, which can lead to blackout of the whole grid.

To date, mainly power converter or inverter-interfaced DGs have been researched, developed, and standardized. This is due to the fact that variable alternative current (AC)/direct current (DC) sources are converted to power grid level through the power converter technology easily and efficiently. This technology also provides a fast response that is required to control the intermittent renewable energy sources for stable and safe operation. The greater the demands for the grid code become, the more standardized information of the inverter-interfaced DGs is required for effective data 
exchange and the interoperability between devices, as they contain various advanced functions, such as adjusting power factor, active power curtailment, Voltage/VAR (V/V) mode setting, LVRT [4,5].

Inverters which have these advanced functions are called smart inverters and are used for many purposes. Particularly in Medium Voltage (MV) microgrids or MV distribution networks, smart inverter-interfaced DGs have increased reliability and transmission efficiency due to use of their advanced functions. The V/V function is one of these, and its purpose is to increase the hosting capacity of DGs and to enhance the voltage stability of the system. Note that it is ineffective to use $\mathrm{V} / \mathrm{V}$ function in Low Voltage (LV) networks. Conventionally, DGs have acted passively in the grids [6-8] and hence their hosting capacity has been limited [9-11]. To increase the hosting capacity of passively operating DGs and to enhance the voltage stability, an On-Load Tap Changer (OLTC) and shunt capacitors have been used to regulate the voltage [10,12]. However, in order to utilize DGs more actively, various V/V functions and control modes have been developed. Improving power factor function and Conservation Voltage Reduction (CVR) method are part of these, and many other types of $\mathrm{V} / \mathrm{V}$ functions have been developed [13,14]. In [15], the reactive power support of DGs was used to mitigate voltage collapse. Inverter control strategy was proposed to allow DGs to support grid voltage during voltage sags in [16]. The limitation of maximum available active and reactive power of PV systems was evaluated in [17]. In [18], the adaptive zoning technique was proposed to recover the grid voltage within allowable limits after disturbances. The conventional V/V functions have been mainly focused on flattening voltage profile or regulating voltage in order to increase hosting capacity of DGs in distribution networks and to enhance the voltage stability. In this paper, new requirements of $\mathrm{V} / \mathrm{V}$ function for purposes other than the voltage regulations are investigated.

The rest of the paper is organized as follows: Section 2 investigates International Electronical Committee (IEC) 61850 and control of DGs. Section 3 describes the problem formulation for investigating new requirements. Section 4 shows simulation results and suggests new requirements of $\mathrm{V} / \mathrm{V}$ functions. Section 5 provides a conclusion and identifies areas for future work.

\section{IEC 61850 and Control of DG}

The standardization of DGs is necessary since the number and type of the energy sources are enormous, and the rating capacity and the forms of DGs are vary significantly. The standards of DGs can effectively control these enormously diverse DGs in distribution networks by exchanging data with other DGs and/or supervisory control systems. The standard contains communication protocols, data set, data exchange procedure, and functions.

IEC 61850-relating to communication networks and systems for power utility automation-was originally defined for data exchange between high-voltage devices in substations. But it is expanding its applicable area to various electric devices, such as DGs, for data exchange and communication protocols [19].

IEC 61850-7-420 defines standardized data models and data set of DGs, and IEC 61850-90-7 defines data models and functions for inverter-interfaced DGs [20,21]. The functions and applications are about connection/disconnection, adjusting maximum generation level and power factor, requesting active power, $\mathrm{V} / \mathrm{V}$ mode setting, frequency management mode, dynamic reactive current support, LVRT/High Voltage Ride-Through (HVRT), voltage/watt management, etc. Of these, this paper focuses on the $\mathrm{V} / \mathrm{V}$ function.

The V/V function can be managed by: (1) a specific DG unit itself; (2) multicast or broadcast of DGs in a specific area; and (3) schedule. In microgrids, control of DGs can be implemented by (1) and (2). For both methods, parameters, such as a slope of $\mathrm{V} / \mathrm{V}$ function, are calculated and provided by supervisory control systems in order to control DG units. The third method, (3), uses prescheduled parameters for services, such as Demand Response (DR) or temperature change. The main purposes of using smart inverter-interfaced DGs are to use them as Virtual Power Plants (VPPs) and to implement DR. The former is mainly applied in Europe and the latter is mainly applied in North America [14]. 
Figure 1 shows the interface of DGs under IEC 61850-90-7 and describes three levels of hierarchy in data exchange, where PCC stands for Point of Common Coupling. The lower section describes autonomous DGs which respond to local conditions. Note that local conditions are unnecessary to DGs if DGs are disconnected from PCC. In this level, fast measurement ability of DG systems is important and predetermined parameters are used to control DG units. In the middle section, the DG Energy Management System (EMS) gives control references to lower-level DGs and is usually used in campuses, buildings, and microgrids. The top section of Figure 1 shows that unidirectional broadcast/multicast signals (such as emergency signals, pricing signals, and DG control mode change signals) are given by utilities. The broadcast/multicast can be implemented hourly, weekly, or seasonally and used for services which do not need fast response of DG units.

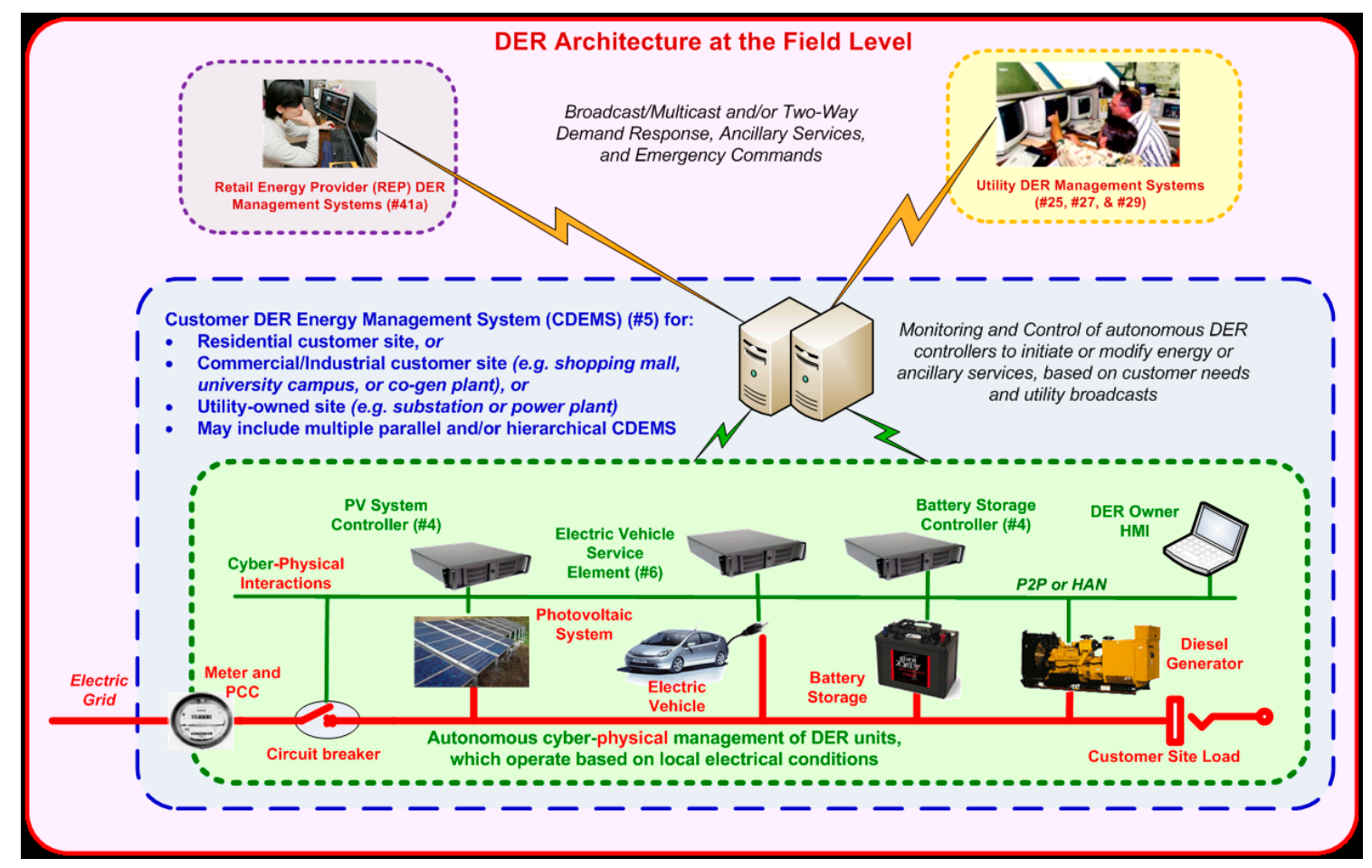

Figure 1. Interface of Distributed Generations (DGs) under IEC 61850-90-7 [21]. DER: Distributed Energy Resources; PCC: Point of Common Coupling, P2P: Peer-to-Peer, HMI: Human-Machine Interface, HAN: Home Area Network.

The Korea Electrotechnology Research Institute (KERI) has been developing coordinated management systems of DGs and DG interfaces in accordance with IEC 61850 and IEC 61850-7-420. To this end, new requirements of $\mathrm{V} / \mathrm{V}$ functions which can effectively manage $\mathrm{DG}$ units in a distribution network are being developed and investigated. In this study, the methods (1) and (2) are applied to calculate the slope of the $\mathrm{V} / \mathrm{V}$ function. The slope of the $\mathrm{V} / \mathrm{V}$ function is expressed as (see Figure 2):

$$
S_{V / V}= \begin{cases}\frac{Q_{\text {avail }}}{V_{O P, \text { min }}-V_{D B, \text { min }},}, & \text { if } V \leq V_{D B, \text { min }} \\ \frac{-Q_{\text {avail }}}{V_{O P, \text { max }}-V_{D B, \text { max }},}, & \text { if } V \geq V_{D B, \text { max }}\end{cases}
$$

where $Q_{\text {avail }}$ is the available reactive power of $\mathrm{DG}, V_{D B, \min }$ and $V_{D B, \max }$ are the minimum and the maximum dead band values (see Figure 2), respectively, for triggering the $\mathrm{V} / \mathrm{V}$ function of inverters. $V_{O P, \min }$ and $V_{O P, \max }$ are the minimum and the maximum voltages, respectively, where $\mathrm{V} / \mathrm{V}$ function operates. However, if the $\mathrm{V} / \mathrm{V}$ curve is within a circular capability curve, $Q_{\text {avail }}$ should always be 
limited below the maximum reactive power $Q_{m a x}$, which is depends on the active power flow $P$ as follows:

$$
Q_{\max }=\sqrt{S_{\text {rate }}^{2}-P^{2}}
$$

where $S_{\text {rate }}$ is the rating of apparent power of the inverter.

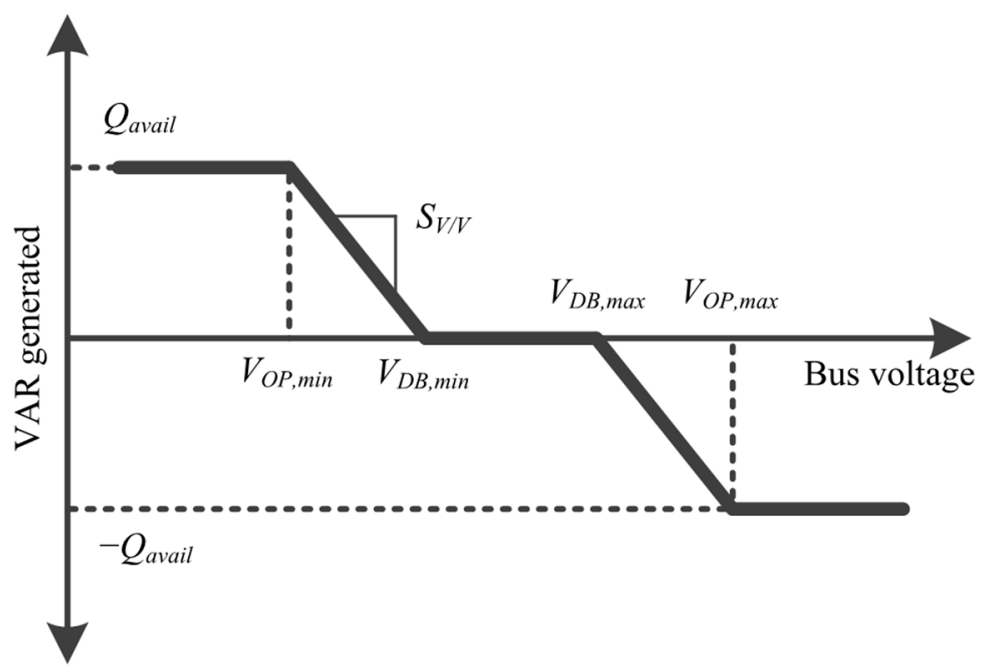

Figure 2. Voltage/VAR function requirement for smart inverters [21].

\section{Problem Formulation}

One of the main purposes of the $\mathrm{V} / \mathrm{V}$ function is to increase the hosting capacity of DGs in distribution networks. Since the hosting capacity has a direct bearing on the voltage profile, the conventional $\mathrm{V} / \mathrm{V}$ function is used to flatten the voltage profile as shown in Figure 2. In this paper, the possibility of utilization of the $\mathrm{V} / \mathrm{V}$ function for another purpose without deteriorating hosting capacity of DGs is investigated. Since loss minimization is the most widely applied objective function in power system studies [22-25], line loss reduction is tested. For this purpose, Particle Swarm Optimization (PSO) and Newton-Raphson power flow calculation is used in the optimization algorithm.

\subsection{Particle Swarm Optimization (PSO)}

PSO is one of heuristic algorithms. Though it does not always guarantee the best solution (the smaller the problem is, the more accurate the solution is), it finds a solution close to the best one and is widely used due to its calculation speed and simplicity. Moreover, it is known to effectively solve nonlinear optimization problems [26] and is hence suitable for solving power system problems. PSO exhibits excellent performance in searching for the global optimum because it can diversify the swarm using a stochastic velocity term [5]. Particles look for the optimal solution in search space based on position, which is learnt heuristically and iteratively. The movement of the particles is based on the following relationships [5]:

$$
\begin{gathered}
V_{i}^{k+1}=V_{i}^{k}+c_{1} \operatorname{rand}_{1}\left(X_{p b, i}^{k}-X_{i}^{k}\right)+c_{2} \operatorname{rand}_{2}\left(X_{g b}^{k}-X_{i}^{k}\right) \\
X_{i}^{k+1}=X_{i}^{k}+V_{i}^{k+1}
\end{gathered}
$$

where $V$ is the velocity vector, $X$ is the position vector, $i$ is the particle index, $k$ is the iteration index, subscripts $p b$ and $g b$ denote for position best and global best, respectively, $c_{1}$ and $c_{2}$ are acceleration constants, and rand $_{1}$ and rand $_{2}$ are random numbers with a uniform distribution in a range between 0.0 and 1.0. The best solution for each particle $i$ until iteration $k, X_{p b, i}^{k}$, memorizes its own best solution 
and the global best solution, $X_{g b}$, memorizes the best solution among the whole particles. Typically, the maximum value of $c_{1}+c_{2}$ is 4 , and an effective initial condition is $c_{1}=c_{2}=2$ [26]. The parameters $c_{1}$ and $c_{2}$ are the elements which impact on the accuracy level of PSO. In this paper, both $c_{1}$ and $c_{2}$ are set to 0.5 grounds for empirical test results. More details can be found in [26].

\subsection{Objective Function and Constraints}

Since the purpose of the optimization algorithm is to minimize line losses of a distribution network, the objective function is formulated as:

$$
J=P_{\text {loss }}+f_{p}
$$

where $P_{\text {loss }}$ is total line losses of a distribution network and $f_{p}$ is a penalty function. The penalty function is incorporated into the objective function in order to increase the value of objective function if constraint conditions are violated. The constraint conditions are as follows:

- $\quad V_{\min } \leq V_{j} \leq V_{\max }$, for all buses

- $\quad-Q_{a v a i l, D G, j} \leq Q_{D G, j} \leq Q_{a v a i l, D G, j}$, for all DG buses

- $Q_{D G, j}=0$, if $V_{D B, \min } \leq V_{j} \leq V_{D B, \max }$

- $\quad P_{\text {gen }}=P_{\text {load }}+P_{\text {loss }}$

where $V_{\min }$ and $V_{\max }$ are the allowable minimum and maximum voltages, respectively, $V_{j}$ is the $j$ th bus voltage, $Q_{a v a i l, D G, j}$ is the available reactive power of a DG installed at $j$ th bus, $Q_{D G, j}$ is the reactive power of a DG installed at $j$ th bus, $P_{\text {gen }}$ is the total generation, and $P_{\text {load }}$ is the total load. To satisfy and reflect the first constraint condition, the penalty function is expressed as:

$$
f_{p}=\left\{\begin{array}{cl}
K_{p}\left(V_{\min }-V_{j}\right) & , \text { if } V_{j} \leq V_{\min } \\
K_{p}\left(V_{j}-V_{\text {max }}\right) & , \text { if } V_{j} \geq V_{\max } \\
0 & , \text { otherwise }
\end{array}\right.
$$

where $K_{p}$ is the positive constant for adjusting the size of the penalty function. Note that overloading on lines and transformers is not considered in the penalty function since there is no such case in this study. The second and the third constraint conditions are handled in the midst of the optimization algorithm, which will be discussed in the next subsection, and the fourth constraint condition is satisfied during the power flow calculation.

\subsection{Optimization Algorithm}

The complete optimization algorithm is shown in Figure 3. The purpose of this algorithm is to minimize line losses by using the V/V function of DGs while maintaining the network voltage profile within the allowable ranges (in order not to deteriorate hosting capacity of DGs). Hence, the control variable (the position vector $X$ ) of the algorithm shown in Figure 3 is reactive power of each DG unit.

The algorithm starts with initialization of parameters and then calculates $X$ and $V$ according to Equations (3) and (4). Then, the algorithm checks if any of $X$ elements exceeds its limit or not (this process is to satisfy the second constraint condition). If it exceeds its limit, it is set to the limit value and if not, the process goes on. With the updated $X$ (reactive power of each DG unit), the power flow calculation is implemented and the objective function $J$ is calculated according to Equations (5) and (6). Subsequently, the algorithm checks if the DG bus voltages are within the range of dead band or not. If any of the DG bus voltages exceeds its dead band range, the algorithm sets the corresponding DG reactive power to 0 and repeats the power flow calculation. If all of them are within the dead band range, $X_{g b}$ and $X_{p b}$ are updated. The whole process is repeated until the iteration number reaches its maximum value which is set at the beginning of the algorithm. The power flow calculation used in this study is Newton-Raphson power flow calculation method referred to in [27]. 


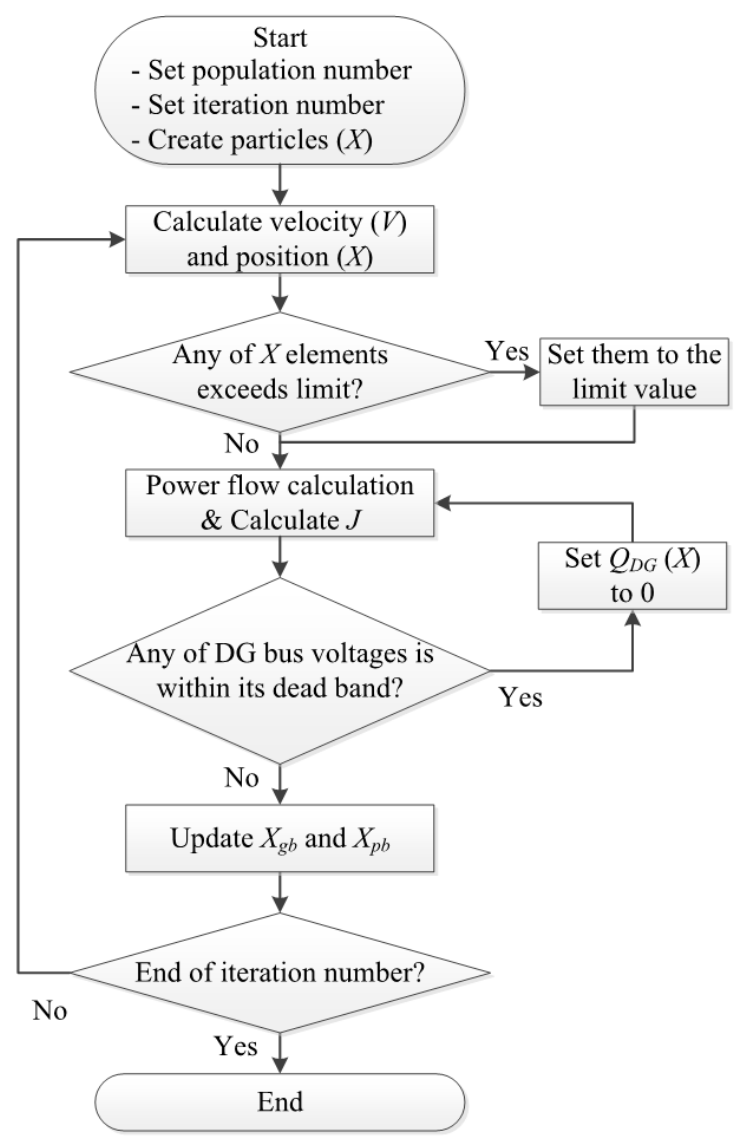

Figure 3. Flow chart of the algorithm.

By implementing the algorithm, the reactive power of each DG unit for loss minimization is calculated. However, the control variable of the $\mathrm{V} / \mathrm{V}$ function is not the reactive power output but the slope of the $\mathrm{V} / \mathrm{V}$ function. This is because this study is focused on the $\mathrm{V} / \mathrm{V}$ curve setting specified in IEC 61850-90-7 as well as the flattening of the voltage profile. Furthermore, optimal power reference signals are updated every five minutes [28]. This could not be faster due to calculation time. Hence, within five minutes, a fixed point power reference cannot cope with the voltage variation whereas the $\mathrm{V} / \mathrm{V}$ curve can. Therefore, by using the output reactive power of DGs acquired from the algorithm, the slope of the $\mathrm{V} / \mathrm{V}$ function can be calculated as:

$$
S_{V / V}=\frac{Q_{D G}}{\Delta V}
$$

where

$$
\Delta V=\left\{\begin{array}{ll}
V-V_{D B, \text { min }}, & \text { if } V \leq V_{D B, \min } \\
V-V_{D B, \max }, & \text { if } V \geq V_{D B, \max }
\end{array} .\right.
$$

Equation (7) can be calculated by using the results of the power flow calculation.

\section{Case Studies and Suggestions for a New Volt/VAR Function}

In order to investigate the effective utilization of an inverter's $\mathrm{V} / \mathrm{V}$ function, the loss minimization algorithm is developed and tested. Note that the loss minimization is one of the various potential ways to use the $\mathrm{V} / \mathrm{V}$ function and the loss minimization is tested in this study to find out the possibility of the $\mathrm{V} / \mathrm{V}$ function for other purposes. 
As shown in Figure 4, Institute of Electrical and Electronics Engineers (IEEE) 37 node test feeder referred to in [29], with slight modification, was used for testing the proposed method. The nominal voltage of the feeder is $4.8 \mathrm{kV}$, which is a MV level [30]. There is an OLTC between bus 799 and 701 as shown in Figure 4. The default value of the reference voltage of the secondary side of OLTC is $1.0167 \mathrm{pu}$. Practically, the secondary side of the OLTC voltage varies from 1.0 to $1.033 \mathrm{pu}$ since the voltage bandwidth is $\pm 0.0167 \mathrm{pu}$. However, the power flow calculation gives a steady state solution and hence the bus voltage of the OLTC should be fixed to a constant value while using Newton-Raphson power flow calculation (usually it is $1.0 \mathrm{pu}$ ). In this study, the OLTC bus voltage is set to 1.0167 according to its reference value. Three DG units, DG1, DG2, and DG3 are connected at bus 720,730 , and 741 , respectively and active power ratings are 1, 1, and $0.5 \mathrm{MW}$, respectively. $V_{\min }, V_{\max }, V_{D B, \min }$, and $V_{D B, \max }$ are $0.95 \mathrm{pu}, 1.05 \mathrm{pu}, 0.99 \mathrm{pu}$, and $1.01 \mathrm{pu}$, respectively. The loads and lines are assumed to be three phase balanced and the load demand for each bus is shown in Table 1 . All loads are assumed to be a constant power model. The line impedances are shown in Table 2 in pu with the base power and voltage of $1 \mathrm{MW}$ and $4.8 \mathrm{kV}$, respectively.

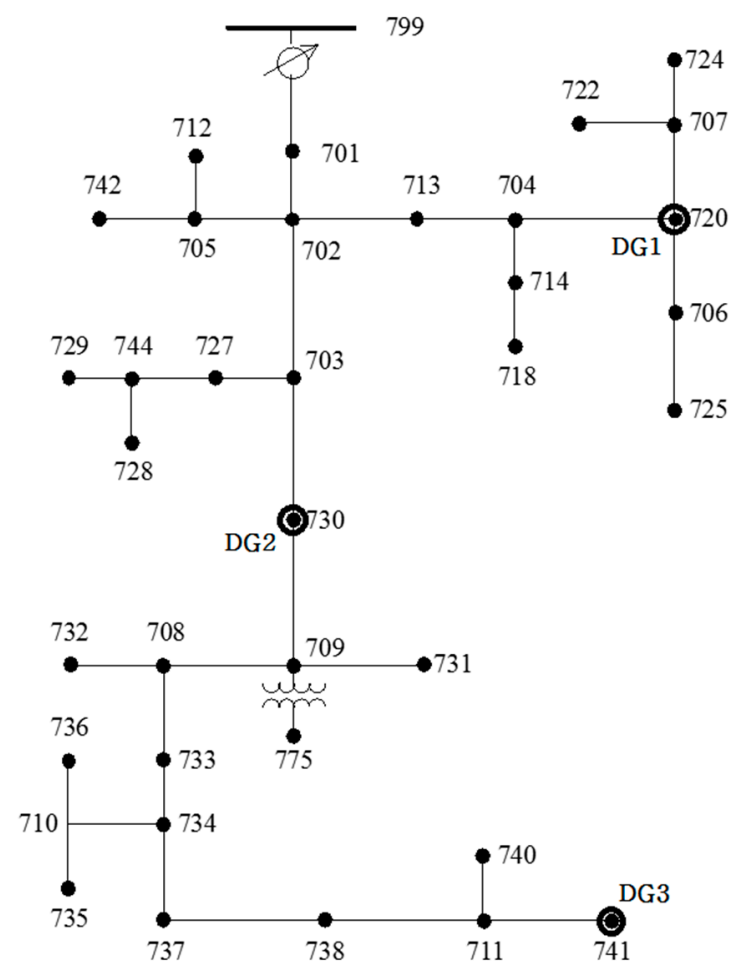

Figure 4. IEEE 37 node test feeder [29].

In total, three cases were studied for considering heavy/light load conditions and full/no load states of DG units. In each case, the voltage profile with the optimal algorithm was compared with other control methods that adjust $S_{V / V}$ by changing $Q_{a v a i l}$. From Equation (1), note that $S_{V / V}$ can be changed by adjusting three variables, $V_{D B}, V_{O P}$, and $Q_{a v a i l}$. However, in this study, only $Q_{\text {avail }}$ is adjusted to vary $S_{V / V}$ for the sake of convenience. The maximum values of $Q_{a v a i l}(100 \%)$ of DG1, DG2, and DG3 are $0.62,0.62$, and 0.31 MVAR, respectively, on the basis of [21], which notices that an inverter applying IEC 61850 standard should be able to operate the power factor of 0.85 with respect to its active power rating. 
Table 1. Load demand of each bus.

\begin{tabular}{ccccc}
\hline \multirow{2}{*}{ Bus Number } & \multicolumn{2}{c}{ Heavy Load Condition } & \multicolumn{2}{c}{ Light Load Condition } \\
\cline { 2 - 5 } & Active Power (MW) & Reactive Power (MVAR) & Active Power (MW) & Reactive Power (MVAR) \\
\hline 701 & 0.6300 & 0.3150 & 0.1260 & 0.0630 \\
712 & 0.0850 & 0.0400 & 0.0170 & 0.0080 \\
713 & 0.0850 & 0.0400 & 0.0170 & 0.0080 \\
714 & 0.0378 & 0.0180 & 0.0075 & 0.0036 \\
718 & 0.0850 & 0.0400 & 0.0170 & 0.0080 \\
720 & 0.0850 & 0.0400 & 0.0170 & 0.0080 \\
722 & 0.1608 & 0.0800 & 0.0322 & 0.0160 \\
724 & 0.0420 & 0.0210 & 0.0084 & 0.0042 \\
725 & 0.0210 & 0.0084 & 0.0042 \\
727 & 0.0420 & 0.0210 & 0.0084 & 0.0042 \\
728 & 0.0630 & 0.0252 & 0.0126 \\
729 & 0.1260 & 0.0210 & 0.0084 & 0.0042 \\
730 & 0.0420 & 0.0400 & 0.0170 & 0.0080 \\
731 & 0.0850 & 0.0400 & 0.0170 & 0.0042 \\
732 & 0.0850 & 0.0210 & 0.0084 & 0.0080 \\
733 & 0.0420 & 0.0400 & 0.0084 & 0.0042 \\
734 & 0.0850 & 0.0210 & 0.0170 & 0.0080 \\
735 & 0.0420 & 0.0400 & 0.0084 & 0.0042 \\
736 & 0.0850 & 0.0210 & 0.0280 & 0.0140 \\
737 & 0.0420 & 0.0700 & 0.0252 & 0.0124 \\
738 & 0.1400 & 0.0620 & 0.0170 & 0.0080 \\
740 & 0.1260 & 0.0400 & 0.0084 & 0.0042 \\
741 & 0.0850 & 0.0210 & 0.0186 & 0.0088 \\
742 & 0.0420 & 0.0441 & 0.0084 & 0.0042 \\
744 & 0.0930 & 0.0210 & 0.4913 & 0.2402 \\
\hline Total & 0.0420 & 1.201 & & \\
\hline
\end{tabular}

Table 2. Line data of the network.

\begin{tabular}{cccc}
\hline & Bus Number & & \multicolumn{2}{c}{ Impedance (pu) } \\
\hline From & To & Resistance & Reactance \\
\hline 79 & 701 & 0.004473 & 0.002951 \\
701 & 702 & 0.003770 & 0.002364 \\
702 & 705 & 0.006928 & 0.002570 \\
705 & 712 & 0.004156 & 0.001542 \\
705 & 742 & 0.005540 & 0.002057 \\
702 & 713 & 0.003849 & 0.002002 \\
713 & 704 & 0.005557 & 0.002892 \\
704 & 714 & 0.001385 & 0.000514 \\
714 & 718 & 0.001385 & 0.000514 \\
704 & 720 & 0.008551 & 0.004449 \\
720 & 707 & 0.015931 & 0.005913 \\
707 & 722 & 0.002078 & 0.000771 \\
707 & 724 & 0.013158 & 0.004885 \\
720 & 706 & 0.006416 & 0.003336 \\
706 & 725 & 0.004850 & 0.001800 \\
702 & 703 & 0.005184 & 0.003251 \\
703 & 727 & 0.004156 & 0.001542 \\
727 & 744 & 0.002993 & 0.001557 \\
744 & 728 & 0.003463 & 0.001285 \\
744 & 729 & 0.004850 & 0.001800 \\
703 & 730 & 0.006416 & 0.003336 \\
730 & 709 & 0.002138 & 0.001112 \\
709 & 708 & 0.006416 & 0.003336 \\
709 & 732 & 0.003421 & 0.001780 \\
708 & 733 & 0.005540 & 0.002056 \\
708 & 734 & 0.003421 & 0.001780 \\
733 & 735 & 0.005987 & 0.003115 \\
734 & 736 & 0.009007 & 0.003343 \\
710 & 740 & 0.003463 & 0.001285 \\
710 & & 0.022165 & 0.008226 \\
734 & 731 & 0.006842 & 0.003559 \\
737 & 0.004276 & 0.002225 \\
711 & 0.004276 & 0.002225 \\
711 & 0.003463 & 0.001285 \\
\end{tabular}




\subsection{Case 1}

In this case, all DG units are injecting full power ( $1 \mathrm{pu})$ into the grid during the condition of heavy load, and the simulation result is shown in Figure 5. Typically, heavy load condition may cause under voltage of the feeder, whereas full load state of DG units may occur overvoltage of the feeder. Both conditions have cancelled out over/under voltage effects and result flat voltage profile (note that all bus voltages are close to the reference voltage of 799 bus when $Q_{\text {avail }}=0 \%$ ) as shown in Figure 5 . By adjusting $Q_{\text {avail }}$ from 0 to $100 \%$, the overall voltage of the feeder is lowered since the voltages of DG buses $(720,730$, and 741$)$ exceed $V_{O P, \max }$ and hence all DG units absorb reactive power according to Equations (1), (7) and (8).

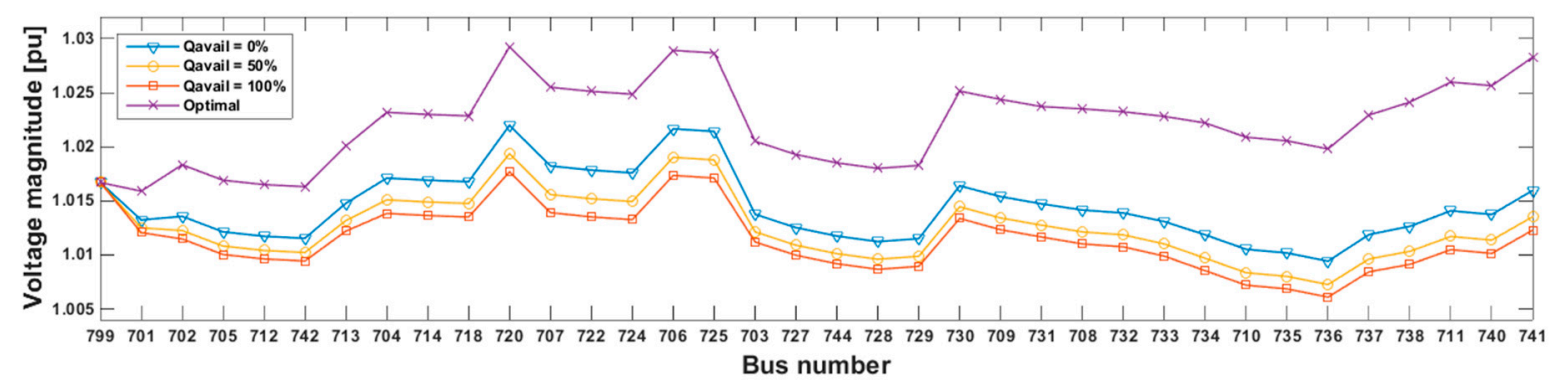

Figure 5. Voltage profiles for heavy load condition while all DG units output full power.

The optimal value of $Q_{\text {avail }}$ is shown in Table 3 (see Case 1 ). Note that all values of $Q_{\text {avail }}$ have a minus sign, which means that the DG units inject reactive power to the feeder even if each DG bus voltage exceeds $V_{D B, \max }$. As shown in Table 4 (see Case 1), the line loss was reduced by applying the loss minimization algorithm. From Figure 5 and Table 4, it can be noticed that the more the bus voltages rise, the more the line loss is reduced. The major reason for this effect is due to the fact that all loads are modeled as a constant power model. For a constant power load model, the load current $I_{L}$ can be expressed as:

$$
I_{L}=\frac{P_{L}}{V_{L}}
$$

where $P_{L}$ is the active power load and $V_{L}$ is the corresponding bus voltage. From Equation (9), it can be noticed that the load current becomes smaller if the bus voltage becomes higher since the power is constant in a constant power load model. The line loss is proportional to the square of line current and hence the line loss is reduced if the load is modeled as a constant power model and the load bus voltage becomes higher.

Table 3. Optimal $Q_{\text {avail }}$ for each case.

\begin{tabular}{cccc}
\hline \multirow{2}{*}{ DG Bus Number } & \multicolumn{3}{c}{$Q_{\text {avail }}$} \\
\cline { 2 - 4 } & Case 1 & Case 2 & Case 3 \\
\hline 720 & $-46.41 \%$ & $-5.63 \%$ & - \\
730 & $-88.21 \%$ & $-12.96 \%$ & - \\
741 & -71.26 & $50 \%$ & - \\
\hline
\end{tabular}

Table 4. Total line losses for each case.

\begin{tabular}{cccc}
\hline \multirow{2}{*}{ Method } & \multicolumn{3}{c}{ Line loss $\mathbf{( k W )}$} \\
\cline { 2 - 4 } & Case 1 & Case 2 & Case 3 \\
\hline$Q_{\text {avail }}=0 \%$ & 29.6 & 69.5 & 3.1 \\
$Q_{\text {avail }}=50 \%$ & 37.2 & 84.0 & - \\
$Q_{\text {avail }}=100 \%$ & 42.5 & 117.7 & - \\
Optimal & 16.2 & 74.3 & - \\
\hline
\end{tabular}


If all DG units output zero power, they behave similarly to reactive compensators. As many studies in the literature have already discussed loss minimization and flattening of the voltage profile using the reactive compensators, the case of zero output power under heavy load condition is omitted in this study.

\subsection{Case 2}

The most significant problem may occur in this case where the system load demand is low and all DG units are injecting full power into the grid. These conditions may cause over-voltage in the feeder. As shown in Figure 6, the voltage profiles are relatively higher than other cases. This is particularly true when $Q_{a v a i l}=0 \%$ and the voltage of some buses $(737,738,711,740$, and 741$)$ exceeds their limit, $1.05 \mathrm{pu}$. As $Q_{\text {avail }}$ increases, the voltage profile is lowered and flattened. However, as mentioned in Case 1, the voltage has to be high in order to decrease the line loss. As shown in Table 4 (see Case 2), the line loss increases as $Q_{a v a i l}$ increases.

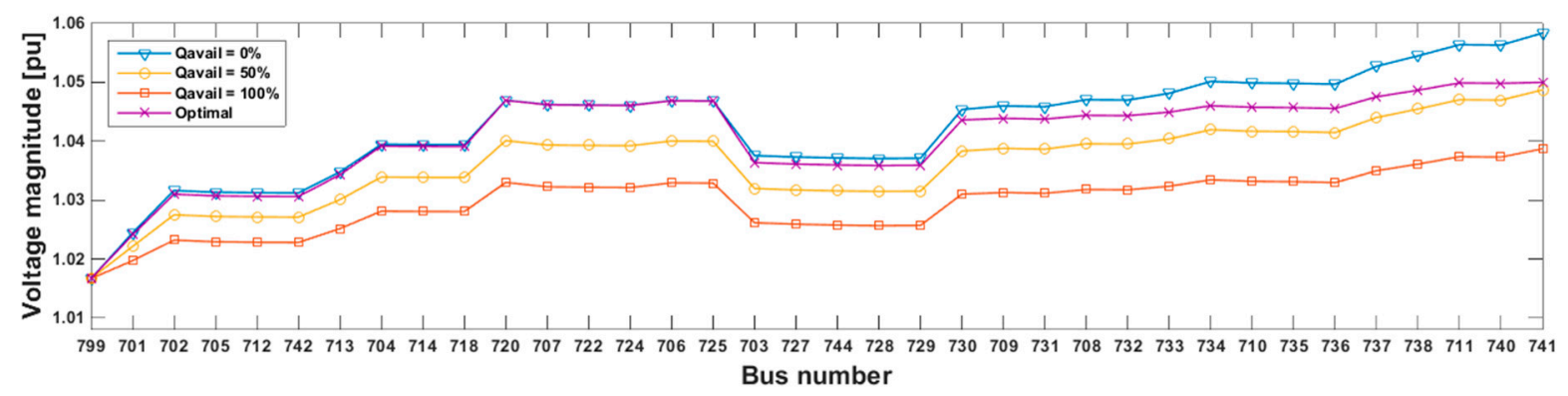

Figure 6. Voltage profiles for light load condition while all DG units output full power.

By implementing the algorithm shown in Figure 3, the optimal values of $Q_{\text {avail }}$ are acquired as shown in Table 3 (see Case 2). Note that $Q_{\text {avail }}$ of DG3 has the value of the plus sign whereas the others (DG1 and DG2) have a minus sign. This means that for a specific feeder condition, some DG units require negative $S_{V / V}$ (the conventional one) whereas the others require positive $S_{V / V}$. The line loss was decreased by applying the optimization algorithm as shown in Table 4 (see Case 2). Note that the case where $Q_{\text {avail }}=0 \%$ shows smaller line loss than the optimal case but the former case violates the voltage constraints.

\subsection{Case 3}

Figure 7 shows the voltage profile of the feeder for light load condition while all DG units output zero power. Since all DG units do not generate power, overvoltage does not occur. When $Q_{\text {avail }}=0 \%$, all DG unit bus voltages are within their dead band, the reactive power compensation is unnecessary. Therefore, the optimization algorithm is not tested in this case. However, it may need to be tested to find out optimal $S_{V / V}$ if $V_{D B}$ and $V_{O P}$ are adjusted.

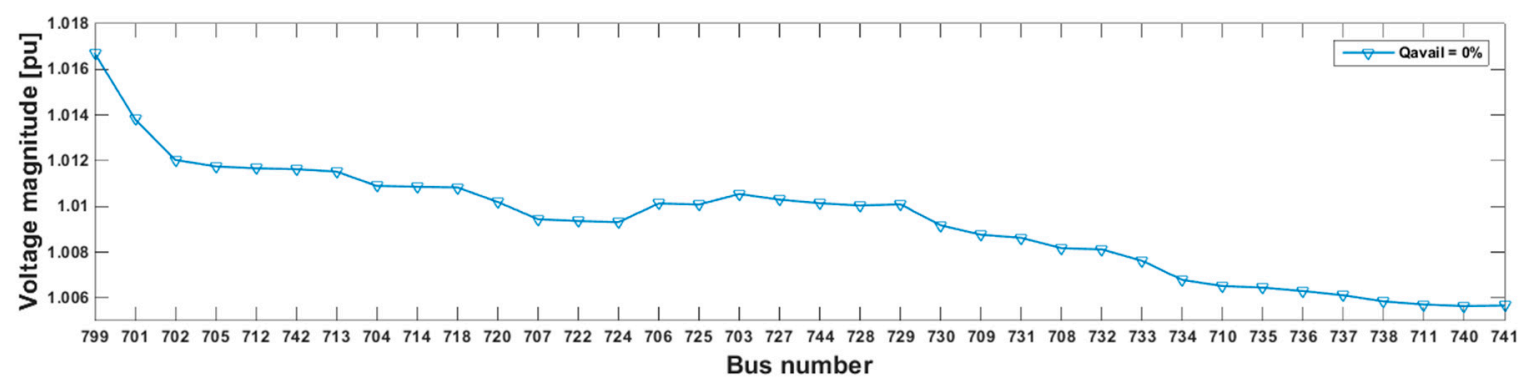

Figure 7. Voltage profiles for light load condition while all DG units output zero power. 


\subsection{Suggestions for a New Volt/VAR Function}

Case studies show that in specific conditions, the slope of the $\mathrm{V} / \mathrm{V}$ function has to be operated in the opposite manner. This means that $S_{V / V}$ has to have a positive value, while it is conventionally a negative value. The positive value of $S_{V / V}$ is needed to reduce line loss by increasing the voltage level and it is effective only for constant power loads as shown in Equation (9). However, in practical power systems, not only constant power loads but also constant current loads and constant impedance loads are contained. This is particularly so in the case of constant impedance loads, where, unlike constant power loads, the load current and hence the line loss is reduced as the bus voltage is decreased. Subsequently, types of load (whether it is a constant power load or a constant impedance load or a constant current load) and the corresponding bus location have to be considered also in order to reduce line loss in practical power systems. Consequently, in order to determine the value each DG unit's $S_{V / V}$, the acquirable and the necessary data are as follows:

- Local time-Using the present local time, the present load condition can be estimated (whether it is a light or a heavy load condition).

- Types of loads-The types of loads (constant power load/constant impedance load/constant current load) affect the sign of $S_{V / V}$. In practice, types of load are mixed, and hence the most dominant type of load at each bus may be used. The most dominant type of load can be determined by extracting ZIP coefficients, which stand for constant impedance $Z$, constant current $I$, constant power $P$ loads. The expressions for active and reactive powers of the ZIP coefficients model are described as [31]:

$$
P=P_{0}\left[Z_{p}\left(\frac{V_{i}}{V_{0}}\right)^{2}+I_{p} \frac{V_{i}}{V_{0}}+P_{p}\right]
$$

where $P$ is the active power at operating voltage $V_{i}, P_{0}$ is the active power at rated voltage $V_{0}$, and $Z_{p}, I_{p}$, and $P_{p}$ are the ZIP coefficients for active power. As shown in Equation (10), constant impedance model depends quadratically on the voltage, and constant current load depends linearly on the voltage. The details of extracting ZIP coefficients are described in [31]. After determining the type of load at each bus as the dominant type, the power flow calculation is implemented with the determined load type.

- Locations of loads-If the constant power loads are dominant in the vicinity of DG unit, the V/V function has to be operated in order to raise the bus voltage whereas if the constant impedance loads are dominant in the vicinity of DG unit, the V/V function has to be operated in the opposite way.

- Bus voltage-The local bus voltage has to be measured to determine whether the conditions are of undervoltage or overvoltage.

- Output active power-The output active power affects the power factor as well as the bus voltage.

- State estimation - Instead of the forecasted data, the state estimation data based on measurements (voltage, power flow) is required to acquire load data since the forecasted data could introduce large uncertainties.

Taking into consideration the above variables, the decision-making process for a value of $S_{V / V}$ is shown in Figure 8 and an operating range for a new $\mathrm{V} / \mathrm{V}$ function is shown in Figure 9. Unlike the conventional $\mathrm{V} / \mathrm{V}$ function shown in Figure 2, in the new $\mathrm{V} / \mathrm{V}$ function, $S_{V / V}$ can be determined as either positive or negative value. The slope $S_{V / V}$ can be formed flexibly within the operating range shown in Figure 9. As shown in Figure 8, the acquirable local data are used to implement an optimization algorithm. In this study, only the constant power load is considered since the constant current load has nothing to do with the voltage and line loss relationship. This is because no matter what the voltage is, the current flowing through the lines due to the constant current load is same. Note that the loss minimization is the objective function in this study. Moreover, the constant power load is more dominant than the constant impedance load in the distribution network [31]. The objective 
function of the optimization algorithm can be determined by the system operator (in this study it is of loss minimization). For instance, at the bus with a voltage magnitude higher than $1 \mathrm{pu}$, when the objective function of the algorithm is to minimize loss, DGs in the vicinity of the constant power load inject the reactive power into the grid. When the objective function is to keep the grid voltage close to $1 \mathrm{pu}$, they absorb the reactive power. The voltage profile has to be considered as a constraint condition since it affects the hosting capacity of DG units. As shown in Figure 9, unlike the conventional V/V function, the positive slope as well as the negative slope has to be contained in the operation range.

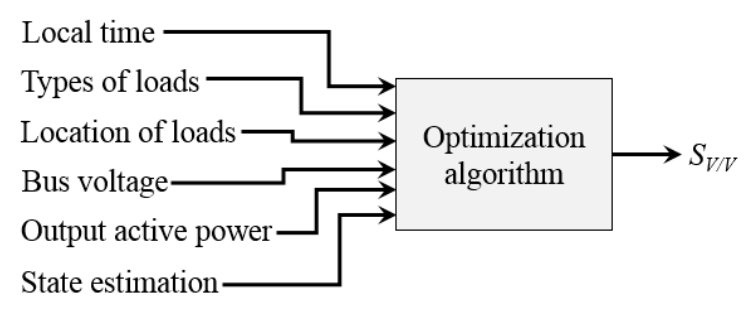

Figure 8. Decision-making process of $S_{V / V}$.

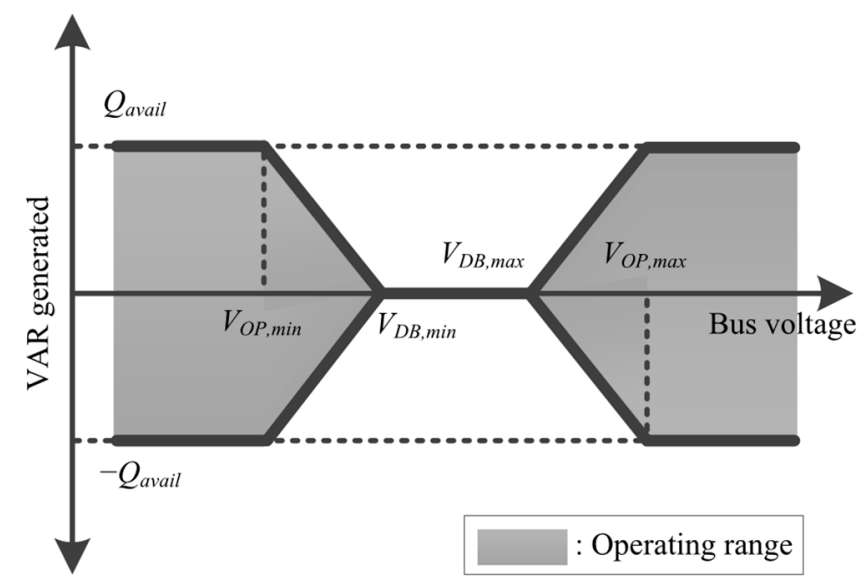

Figure 9. Operating range for a new Volt/VAR function.

\section{Conclusions and Future Works}

This paper proposes new requirements for V/V function in IEC 61850 for smart inverter-interfaced DG control. The conventional V/V function acts passively only for increasing hosting capacity of DG units and for enhancing the voltage stability whereas the proposed requirements can be used also for other purposes, such as loss minimization. Since IEC 61850 is the most widely used standard for DG control, incorporating new requirements for many purposes can make DGs useful in various aspects in order to enhance the efficiency of power systems. For the proposed requirements, the local time, types of loads, and location of loads have to be provided for determining the slope of $\mathrm{V} / \mathrm{V}$ function $\left(S_{V / V}\right)$ and a new operating range of $\mathrm{V} / \mathrm{V}$ function.

For future works, objective functions other than loss minimization have to be considered in order to prove the effectiveness of the proposed requirements. The other types of loads, such as constant current load and constant impedance load, have to be also considered since in this study, only constant power loads are contained in the system. As discussed in Section 4, the other types of loads may affect the process of determining the optimal $S_{V / V}$ differently. For instance, the constant power load increases the line loss if the voltage drops, whereas the constant impedance load increases the line loss if the voltage rises. 
Acknowledgments: This research was supported by Korea Electrotechnology Research Institute (KERI) Primary research program through the National Research Council of Science \& Technology (NST) funded by the Ministry of Science, ICT and Future Planning (MSIP) (No. 16-12-N0101-07).

Author Contributions: Yun-Su Kim conceived and designed the simulations; Gyeong-Hun Kim performed the simulations; Jae-Duck Lee and Changhee Cho analyzed the data; Yun-Su Kim wrote the paper; Changhee Cho supervised the paper.

Conflicts of Interest: The authors declare no conflict of interest.

\section{References}

1. Electric Power Research Institute. The Integrated Grid: Realizing the Full Value of Central and Distributed Energy Resources; Electric Power Research Institute (EPRI): Palo Alto, CA, USA, 2014.

2. Electric Power Research Institute. Integrating Smart Distributed Energy Resources with Distribution Management Systems; EPRI: Palo Alto, CA, USA, 2012.

3. Meibom, P.; Hilger, K.B.; Madsen, H.; Vinther, D. Energy comes together in Denmark: The key to a future fossil-free Danish power system. IEEE Power Energy Mag. 2013, 11, 46-55. [CrossRef]

4. Electric Power Research Institute. Common Functions for Smart Inverters; EPRI: Palo Alto, CA, USA, 2014.

5. Chung, I.-Y.; Liu, W.; Cartes, D.A.; Collins, E.G.; Moon, S. Control methods of inverter-interfaced distributed generators in a microgrid system. IEEE Trans. Ind. Appl. 2010, 46, 1078-1088. [CrossRef]

6. Chowdhury, S.; Chowdhury, S.P.; Crossely, P. Microgrids and Active Distribution Networks; Institute of Engineering and Technology (IET): London, UK, 2009.

7. Pudjianto, D.; Ramsay, C.; Strbac, G. Virtual power plant and system integration of distributed energy resources. IET Renew. Power Gener. 2007, 1, 10-16. [CrossRef]

8. Boehme, T.; Harrison, G.P.; Wallace, A.R. Assessment of distribution network limits for non-form connection of renewable generation. IET Renew. Power Gener. 2010, 4, 64-74. [CrossRef]

9. Bignucolo, F.; Caldon, R.; Prandoni, V. Radial MV networks voltage regulation with distribution management system coordinated controller. Elect. Power Syst. Res. 2008, 78, 634-645. [CrossRef]

10. Hallberg, P. Active Distribution System Management-A Key Tool for the Smooth Integration of Distributed Generation; Eurelectric: Brussels, Belgium, 2013.

11. Caldon, R.; Spelta, S.; Prandoni, V.; Turri, R. Co-ordinated voltage regulation in distribution networks with embedded generation. In Proceedings of the 18th International Conference and Exhibition on Electricity Distribution, Turin, Italy, 6-9 June 2005; pp. 1-4.

12. Viawan, F.A.; Karlsson, D. Voltage and reactive power control in system with synchronous machine-based distributed generation. IEEE Trans. Power Deliv. 2008, 23, 1079-1087. [CrossRef]

13. Navigant. Dynamic Volt/VAR Control Architectures; Navigant: Boulder, CO, USA, 2014.

14. Saadeh, O. DER Management Systems 2014: Technology, Deployments and Market Size; Green Tech Media (GTM): Boston, MA, USA, 2014.

15. Rogers, K.M.; Klump, R.; Khurana, H.; Aquino-Lugo, A.A.; Overbye, T.J. An authenticated control framework for distributed voltage support on the smart grid. IEEE Trans. Smart Grid 2010, 1, 40-47. [CrossRef]

16. Miret, J.; Camacho, A.; Castilla, M.; de Vicuña, L.G.; Matas, J. Control scheme with voltage support capability for distributed generation inverters under voltage sags. IEEE Trans. Power Electron. 2013, 28, 5252-5262. [CrossRef]

17. Delfino, F.; Procopio, R.; Rossi, M.; Ronda, G. Integration of large-size photovoltaic systems into the distribution grids: A p-q chart approach to assess reactive support capability. IET Renew. Power Gener. 2010, 4, 329-340. [CrossRef]

18. Barr, J.; Majumder, R. Integration of distributed generation in the Volt/VAR management system for active distribution networks. IEEE Trans. Smart Grid 2015, 6, 576-586. [CrossRef]

19. International Electrotechnical Commission. Communication Networks and Systems for Power Utility Automation; IEC 61850; IEC: Geneva, Switzerland, 2013.

20. International Electrotechnical Commission. Communication Networks and Systems for Power Utility Automation-Part 7-420: Basic Communication Structure; IEC 61850-7-420; IEC: Geneva, Switzerland, 2013. 
21. International Electrotechnical Commission. Communication Networks and Systems for Power Utility Automation-Part 90-7: Object Models for Power Converters in Distributed Energy Resources (DER) Systems; IEC/TR 61850-90-7; IEC: Geneva, Switzerland, 2013.

22. Kryonidis, G.C.; Demoulias, C.S.; Papagiannis, G.K. A nearly decentralized voltage regulation algorithm for loss minimization in radial MV networks with high DG penetration. IEEE Trans. Sustain. Energy 2016, 7, 1430-1439. [CrossRef]

23. Mahmoud, K.; Yorino, N.; Ahmed, A. Optimal distributed generation allocation in distribution system for loss minimization. IEEE Trans. Power Syst. 2016, 31, 960-969. [CrossRef]

24. Rao, R.S.; Ravindra, K.; Satish, K.; Narasimham, S.V.L. Power loss minimization in distribution system using network reconfiguration in the presence of distributed generation. IEEE Trans. Power Syst. 2013, 28, 317-325. [CrossRef]

25. Atwa, Y.M.; El-Saadany, E.F.; Salama, M.M.A.; Seethapathy, R. Optimal renewable resources mix for distribution system energy loss minimization. IEEE Trans. Power Syst. 2010, 25, 360-370. [CrossRef]

26. Valle, Y.; Venayagamoorthy, G.; Mohagheghi, S.; Hernandez, J.; Harley, R. Particle swarm optimization: Basic concepts, variants and applications in power systems. IEEE Trans. Evol. Comput. 2008, 12, 171-195. [CrossRef]

27. Bergen, A.R.; Vittal, V. Power Systems Analysis, 2nd ed.; Prentice Hall: Upper Saddle River, NJ, USA, 2006.

28. Kundur, P. Power System Stability and Control; McGraw-Hill: New York, NY, USA, 2006.

29. Distribution System Analysis Subcommittee. Available online: http://ewh.ieee.org/soc/pes/dsacom/ testfeeders / (accessed on 16 February 2016).

30. Puret, C. MV Public Distribution Networks throughout the World; Schneider Electric Cahier Technique: Rueil-Malmaison, France, 1992.

31. Bokhari, A.; Alkan, A.; Dogan, R.; Diaz-Aguiló, M.; de León, F.; Czarkowski, D.; Zabar, Z.; Birenbaum, L.; Noel, A.; Uosef, R.E. Experimental Determination of the ZIP coefficients for modern residential, commercial, and industrial loads. IEEE Trans. Power Deliv. 2014, 29, 1372-1381. [CrossRef]

(C) 2016 by the authors; licensee MDPI, Basel, Switzerland. This article is an open access article distributed under the terms and conditions of the Creative Commons Attribution (CC-BY) license (http://creativecommons.org/licenses/by/4.0/). 